\section{$\underset{\substack{\text { hommes } \\ \text { \& migrations }}}{ }$}

\section{Hommes \& migrations}

Revue française de référence sur les dynamiques

migratoires

$1315 \mid 2016$

Ondes de choc

\title{
Éloi Laurent, Nos mythologies économiques
}

Paris, Les liens qui libèrent, 2016, 106 p., $12 €$

\section{Mustapha Harzoune}

\section{(2) OpenEdition}

\section{Journals}

\section{Édition électronique}

URL : http://journals.openedition.org/hommesmigrations/3760

DOI : 10.4000/hommesmigrations.3760

ISSN : 2262-3353

\section{Éditeur}

Musée national de l'histoire de l'immigration

\section{Édition imprimée}

Date de publication : 1 juillet 2016

Pagination : 151-152

ISBN : 978-2-919040-36-0

ISSN : 1142-852X

\section{Référence électronique}

Mustapha Harzoune, «Éloi Laurent, Nos mythologies économiques », Hommes \& migrations [En ligne], 1315 | 2016, mis en ligne le 01 juillet 2016, consulté le 24 septembre 2020. URL : http:// journals.openedition.org/hommesmigrations/3760; DOI : https://doi.org/10.4000/ hommesmigrations.3760 
dans le pays avec sa mère. Is sont reçus comme des rois. C'est là qu'it découvre le mensonge. Le culte de la personnalité du despote de ce petit État totalement fermé au reste du monde contredit le communisme généreux et empreint d'espérance auquel veut tellement croire sa mère. Comment appartenir quand toute allégeance inconditionnelle est un mensonge? teune adulte, it se rend dans le pays de son père. D'abord séduit par cette famille mauritanienne respectée, it accepte même de jouer le rôle d'inter eesceur avec Dieu, lui qui ne croit pas.I embrasserait bien cet héritage quand it se rend compte quesa grand mère-st esclavagiste et que son père n'a jamais osé lutter contre cette "tradition ".

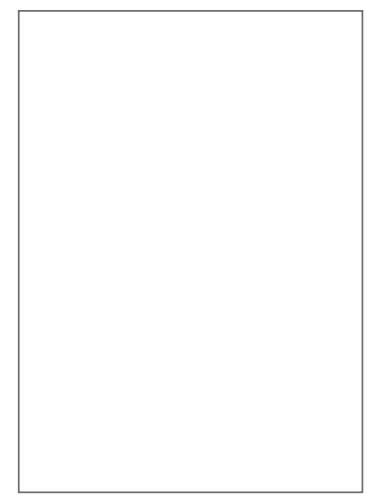

Éloi Laurent Nos mythologies économiques

Paris, Les liens qui libèrent, 2016, 106 p., $12 €$

Éloi Laurent tire à boulets rouges sur un mythe devenu le plus petit dénominateur commun d'une " pensée » qui court les bistrots, les tables dominicales, les émissions télévisées et autres tribunes politiciennes : le chiffre fait roi, le chiffre érigé en instance supérieure, l'économie devenue l'alpha et l'oméga de toute action et politique, et qui rabaisse la vie à deux
Appartenir n'est pas simple quand on ne peut pas se mentir à soi même, et quand on aime la liberté. N'apparte nir est une force. Et s'il faut appartenir alors cesera "au pays de la littérature, eelui qu'avaient cartographié Bradbury et Truffaut. Fahrenheit 451: un monde où les lives sont impitoyablement détruits et où une poignée de résistants obstinés les apprennent par cour, deve nant des hommes lives, les porteurs du meilleur de l'humanité. "Alors Karim Aliské se met à écrire pour enfin " (S') APPARTEAMR ".

Chez le même éditeur, paraitra en novembre 2016 un roman graphique: S'appartenir, scénario de Karim Miskéet dessin d'Antoine Silvestri.

Eatherine Guilyardi

interrogations : " combien ça coûte? ", " combien ça rapporte ? ". Il fut un temps où cette attitude relevait du vulgaire. Aujourd'hui, on la sert ad nauseam, sous couvert de "responsabilité », de "réalisme » et d' "impératif ». "Du coup, qui veut paraitre important (...) fait l'économiste."

II y a urgence, car l'économie " est une mythologie qui désenchante le monde " : exit la part rêvée et poétique de l'existence, effacées les couleurs d'un monde indocile à la triste logique statistique. L'étonnant est que cette " tutelle du chiffre", cette économie devenue "la grammaire de la politique ", est un sophisme, "une mythologie " qui se (et nous) trompe doublement : en perdant de vue l'essentiel et en (nous) faisant 
gober des mensonges. Éloi Laurent déploie son propos en trois thèmes : le néolibéralisme, l'écolo-scepticisme et la social-xénophobie pour dire le fait que les extrêmes droites substituent désormais au "trop d'immigrés " d'hier un " trop d'immigrés pour trop peu de ressources disponibles ».

Cinq «mythes » sont alors déboulonnés: le "grand remplacement ", le " coût économique insupportable » et les charges sociales "insoutenables " de l'immigration, le mythe du " pauvre Blanc, du périurbain oublié " et l'impossible assimilation des immigrés.

L'auteur ne refuse pas la discussion chiffrée, au contraire. À chaque fois et à chaque entrée, statistiques, rapports, études économiques ou démographiques à l'appui, il montre que ces "mythes " sont des mystifications : le "grand remplacement " est une absurdité démographique. Ce qui coûte ce ne sont pas les immigrés contributeurs nets aux budgets sociaux - mais le "grand appauvrissement " qui se double d'inégalités territoriales que le mythe du périurbain oublié occulte en négligeant " de comprendre l'ampleur des inégalités dont sont victimes les territoires défavorisés, en ne voulant voir que la couleur de la peau de leurs habitants". Et sur l'impossible assimilation des personnes immigrées et de leurs rejetons, ce n'est pas l'origine qui pose problème mais les "chances" offertes aux uns et aux autres " de pouvoir s'émanciper de leur origine pour devenir socialement françaises ».

Reste l'essentiel. Après Abdelmalek Sayad, Éloi Laurent refuse de réduire le débat sur l'immigration à un exercice comptable et faire le jeu des xénophobes - trier entre les " bons » et les « mauvais » immigrés. « II serait abject Mustapha Harzoune

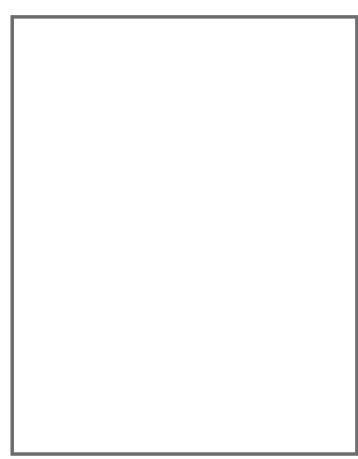

\section{Bruno Loth \\ Dolorès}

Paris, La Boîte à bulles, 2016, 80 p., $18 €$

Février 2015. L'histoire s'ouvre dans une maison de retraite bordelaise. Alignées en rang d'oignon devant un poste de télévision, quatre fringantes vénérables devisent et se chambrent, un peu. "Moi, un bateau va venir me chercher " répète Marie. "C'est pas un bateau qui va venir te chercher, c'est l'ambulance " lui répond une autre. La vie s'expose, dérisoire et tragique, les corps abîmés, fatigués et les mémoires devenues inutiles. Marie inquiète ses filles et le personnel de l'établissement. On ne la reconnaît plus. Son état de santé semble se dégrader. Depuis peu, elle se fait appeler Dolorès et se met à parler en espagnol, elle qui jamais n'a pratiqué cette langue. Étonnant. Comme est étonnant le fait que ses deux filles ignorent tout de son enfance, plus exactement de la vie avant l'orphelinat, quand, à l'âge de sept ans, elle fut adoptée. Alors, par amour pour cette femme qui leur a donné la vie et les a élevées seule, 